\title{
SOBRE LOS MODOS DE CONOCER EL DERECHO. O DE CÓMO CONSTRUIR EL OBJETO JURÍDICO.
}

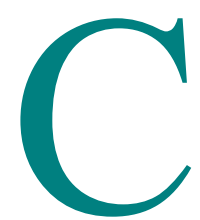

omencemos con un pequeño experimento. Leamos los siguientes textos de un reputado sociólogo, pero dejemos como incógnita, inicialmente, el objeto al que sus afirmaciones se refieren y que representaré como «*»).

1. «Desde el punto de vista sociológico el * cumple funciones coordinadoras e integradoras. En estadios más primitivos, las funciones sociales de coordinar e integrar solían ejercerlas ciertos personajes como los sacerdotes o los reyes».

2. «Como muchas otras habilidades sociales, la determinación del * se desarrolló hasta su nivel actual a través de los siglos, en estrecha relación con el crecimiento de exigencias sociales muy concretas, entre las que, en primer término, se encuentra la necesidad humana de coordinar y sincronizar la serie de actividades entre sí».

3. «Así pues, lo que llamamos es, en primer lugar, un marco de referencia que sirve a los miembros de un cierto grupo y, en última instancia, a toda la humanidad, para erigir hitos reconocibles, dentro de una serie continua de transformaciones del respectivo grupo de referencia».

Seguramente se nos ocurrirán distintas hipótesis para despejar el interrogante acerca del objeto al que aluden estas frases. Parece, en efecto, que se ha de tratar de un objeto social, que se produce y se transforma con el cambio y la evolución de los grupos humanos, pero al que se dota en cada momento de una apariencia objetiva tal que semeja poseer una realidad permanente e inmutable. En realidad, el autor de los textos es Norbert Elias y trata en ellos de la idea del tiempo (sustitúyase el signo «*» por el término «tiempo»), precisamente en su 
obra Sobre el tiempo ${ }^{1}$. Pero, ¿no se nos pudo ocurrir que se refería al derecho? ¿No se suelen presentar con la misma apariencia de objetividad, necesidad y certeza los productos jurídicos, fruto, en realidad, de una elaboración social contingente y condicionada, y construidos y explicados con el instrumental lingüístico que proporcionan no sólo la teoría jurídica, sino también las demás ciencias, conocimientos y creencias socialmente vigentes en cada momento?

Permítase un último texto de Elias, referido a su tema, pero que avanza una hipótesis general sobre los mecanismos de sustantivización objetivante que pudiéramos entender operantes también, a menudo, al hablar del derecho.

«Al reflexionar sobre el problema del tiempo, no es difícil que nos equivoque la forma sustantivada del concepto. Ya en otro lugar indiqué que hablar y pensar con sustantivos objetivantes, como suele hacerse, dificulta mucho la percepción del nexo entre eventos. Esta convención del lenguaje recuerda un poco la tendencia de los antiguos, todavía no desaparecida por completo, de personificar las abstracciones. El obrar con justicia se convirtió en la diosa justicia. Hay muchísimos ejemplos de la coacción que un lenguaje social normalizado ejerce sobre el individuo hablante para que emplee sustantivos objetivantes. Piénsese si no en frases como «el viento sopla» o «el río fluye», como si el viento fuera otra cosa que el soplar y el río distinto del fluir. ¿Hay acaso un viento que no sople y un río que no fluya?» ${ }^{2}$

¿No cabría entender que la misma mecánica social de objetivización de lo que no es sino un producto más de los mecanismos de la comunicación social, se esconde tras afirmaciones como la de que «el derecho obliga», como si realmente pudiera existir un derecho que no obligase?

Precisamente lo que aquí pretendo sostener es que el derecho es un producto social que se constituye en el seno de la comunicación lingüística. Según esta tesis, el derecho obtiene su objetividad esencial en sus encarnaciones lingüísticas y su correspondiente reflejo en el imaginario social. Con una fórmula un tanto paradójica, me atrevería a decir que, bajo esta óptica, el derecho es lo que se dice sobre el derecho. Y si esto es así, si el objeto derecho se constituye y se recrea permanentemente

${ }^{1}$ Elias, N., Sobre el tiempo, México, etc., Fondo de Cultura Económica, 1989, trad. de G. Hirata, 1989. Los textos citados se encuentran, respectivamente, en págs. 64, 136, 84.

${ }^{2}$ Elias, N. op. cit., p. 53. 
al hablar de él ${ }^{3}$, a tal constitución contribuye todo discurso sobre el derecho que pueda tener efectos sobre la forma ulterior de entender y vivir lo jurídico en la sociedad correspondiente, bien sea porque se consolide, bien porque se modifique en algún punto la imagen del sistema jurídico socialmente vigente y operante. Y esto vale lo mismo para el discurso dogmático que para el discurso de las ciencias sociales sobre el derecho; lo mismo, como trataré de nuevo de fundamentar más adelante, para las afirmaciones que sobre el derecho se realizan desde los llamados, desde Hart, puntos de vista interno o externo. Únicamente aquel discurso que se pueda acreditar como perfectamente irrelevante en cuanto a su repercusión o sus consecuencias sobre el objeto derecho, sobre el que versa, se podrá entender como externo o carente de una dimensión de relevancia jurídica.

¿Acaso, tras el ropaje de la cientificidad, no son y no se pretenden influyentes sobre el modo de concebir y de practicar el derecho, discursos acerca de la opinión social sobre las normas, o sobre los condicionamientos clasistas de su aplicación, o sobre la admisibilidad o no en un derecho justo de desigualdades sociales jurídicamente sancionadas? Y más claramente aún ¿no está toda la operatividad de las llamadas fuentes del derecho, cualquiera que sean las que como tales funcionen en un determinado sistema jurídico, mediatizada no sólo por una serie de factores históricos y objetivos, sino también y necesariamente por su imbricación en una teoría del derecho dominante, de forma que cabe entender que ningún sistema de fuentes puede constituirse y operar sin una teoría del derecho anterior o, cuando menos, simultánea, que lo justifique frente a otros sistemas posibles?

Ciertamente no es esa una característica original ni exclusiva del derecho y de la teoría jurídica que lo crea y recrea. El mismo ejemplo de la idea y la vivencia social del tiempo, con el que comencé, lo muestra así. Y existe toda una larga lista ya de teorías sociales que se pueden invocar en apoyo de esta idea de «construcción social de la realidad», desde Wittgenstein a la sociología fenomenológica o la etnometodología, o desde Habermas y su reinterpretación del concepto de «mundo de la vida» hasta Luhmann y su idea de la recursividad de los (sub)sistemas sociales, que generarían incluso sus propias teorías como parte

${ }^{3}$ «La vivencia de los procesos sociales constituye una parte integrante del mismo proceso. No sucede así, por el contrario, respecto de lo que llamamos «naturaleza», es decir, del plano físico del Universo» (Elias, N., op. cit., p. 91). Y la analogía con el tiempo, como producto social, sigue siendo ilustradora: «Ha de afirmarse con certeza que la actividad de determinar el tiempo y el concepto del tiempo no deben considerarse de manera aislada, pues pertenecen indivisiblemente a una imagen global que los hombres poseen acerca de su mundo y de las circunstancias en que viven» (ibid., p. 195). 
del proceso que produce en cada sistema su particular «sentido», a fin de hacer posible la constitución de sus elementos mediante sus elementos. Pero lo que creo que en buena parte está por hacer es una aplicación de esos enfoques al derecho y entre los juristas.

En efecto, atender como criterio preferente al de la incidencia del discurso sobre su propio objeto, puede ofrecer una doble virtualidad a la hora de clasificar y evaluar el conocimiento del derecho. Por un lado, rompe con una división que creo en buena parte falaz o «ideológica», en el sentido de inducida por requisitos funcionales del sistema jurídico y del sistema social en general (incluido el sistema académico) y no producida por objetivos e ineludibles requisitos epistemológicos o metodológicos. Me refiero a la división entre conocimiento dogmático, o práctico, o «interno» del derecho, por una parte, y conocimiento científico o «externo», por otra. Si todo discurso sobre el derecho puede influir sobre el modo de entenderse y operar el derecho, si todo discurso sobre el derecho, incluso el que se pretende meramente descriptivo, coadyuva a la modelación del objeto sobre el que versa o al que describe, tenemos que no sólo la ciencia «del derecho, sino también la ciencia «sobre» el derecho están comprometidas en y con la práctica del derecho, en su permanente creación y recreación social.

Con ello se rompería, al menos en parte, el esquema «ideológico» con el que se justifican tanto las divisiones epistemológicas habituales cuando se habla del estudio del derecho como la ubicación social y política de los juristas. Así, acostumbramos a establecer una gradación en la responsabilidad por los productos jurídicos (normas generales, sentencias, dictámenes, teorías) a tenor de la cual toda responsabilidad en la creación del derecho es política y radica fuera de los límites en los que los operadores jurídicos y los científicos del derecho se desenvuelven. Frente a esa responsabilidad meramente política en la configuración del derecho, los operadores jurídicos (jueces, abogados, burócratas...), trabajarían con un material que en todo o en su mayor parte les viene dado y acabado, por lo que estarían en amplia medida exentos de responsabilidad respecto de los contornos del producto con que proceden. Y, más allá, prácticamente liberados de modo pleno de una tal responsabilidad, se hallarían quienes estudian el derecho, ya sea en clave «dogmática» o «científica» ocupados en describir lo que sería una realidad plenamente preexistente a su discurso.

Pero ¿no hay algo de incoherente en el intento de presentar esta visión distanciada y objetivista de la teoría del derecho respecto de su objeto y, al mismo tiempo, continuar con la práctica habitual, tanto entre «dogmáticos» como entre «científicos» del derecho, de introducir la crítica a las normas vigentes, o a su interpretación dominante, o a la línea jurisprudencial o a la interrelación entre derecho y sociedad? ¿No 
se contiene en toda crítica del derecho que no quiera ser artificio intelectual gratuito, una intencionalidad «política» y un tácito reconocimiento de que la teoría tiene alguna virtualidad conformadora sobre su propio objeto? Tal parece a veces como si la teoría del derecho, en cualquiera de sus manifestaciones, dogmáticas o científicas, se escudara en su condición de teoría para no asumir la parte de responsabilidad que le toca en la configuración de la práctica jurídica, o para presentar el producto de su crítica con la misma pátina de necesidad con que supuestamente se plantea el derecho «objetivo» criticado, si bien frente a esa necesidad o intangibilidad «jurídica» de éste, se opondría la necesidad o verdad «científica» de la crítica. Pero en los campos en que la práctica no puede constituirse y subsistir sin la teoría, la descomposición y separación total de teoría y práctica a efectos epistemológicos, no puede conducir más que al ocultamiento de los mecanismos «teóricos» que mueven la práctica, a la sustancialización u ontologización de los conceptos con que en esa práctica se opera $\mathrm{y}$, en suma, al camuflaje de los resortes operativos del sistema jurídico. Y ahí puede manifestarse con toda su fuerza la paradoja: la más crítica de las teorías del derecho puede desempeñar el mismo papel de respaldo o sanción del orden jurídico constituido que la más apologética de las doctrinas sobre el mismo.

Y no se trata de que en lo que estoy diciendo privilegie el valor de la crítica por la crítica, o la necesidad de que al vigente sistema jurídico-político se le oponga cualquier alternativa, elaborada o puramente quimérica, en nombre de la crítica. No hay que descartar a priori que vivamos en el mejor de los mundos jurídicos posibles. Pero si se puede aspirar a que, tanto para el mantenimiento como para el cuestionamiento de sus estructuras, la teoría sea consciente de su verdadero papel. Al menos el conocimiento y su teoría habrán avanzado si dejan de ser meros resortes funcionales e inconscientes de aquellas estructuras y se plantean en términos conscientes su componente político y de co-responsabilidad. Por ejemplo, se podrá seguir hablando de fuentes del derecho en el mismo sentido en que se hace, pero con la conciencia de que sólo a efectos analíticos o de un cierto lenguaje convencional cabe mantener divisiones tales, pues si el derecho es lo que se dice sobre el derecho, todo lo que se diga sobre los mecanismos de su creación estará creando esos mecanismos y, a la vez, condicionado por ellos. La doctrina que habla de las fuentes del derecho (y también cualquier afirmación vulgar o cualquier expresión legal o jurisprudencial al respecto) tiene que verse como fuente del derecho, o, por mejor decir, metafuente, fuente de las fuentes del derecho.

Lo importante del derecho es que funcione. El derecho llega a existir por una necesidad funcional del sistema social, no como producto 
de la reflexión intelectual. Pero, en el momento en que los individuos tratan de gobernar aquel elemento organizador, valiéndose de la reflexión sobre el mismo, se plantea el derecho en términos de «validez»: deja de ser mecánica social irreflexiva o espontánea y pasa a ser producto de una teoría en cuanto a su conformación y funcionamiento, manteniéndose su función ${ }^{4}$; es decir, será derecho lo que opere como derecho bajo las condiciones de validez impuestas por el discurso teórico- práctico 5 .

$\mathrm{Si}$, como suele afirmarse, el derecho moderno tiene como uno de sus caracteres estructurales el de regular sus propios procedimientos de creación y legitimación ${ }^{6}$ (una vez que se ha desvinculado suficientemente de su implicación en otros constructos sociales más amplios, como el mito, la tradición religiosa o moral, etc.), ocurriría que el discurso constitutivo de la realidad derecho pasa a ser un discurso exclusivo sobre el derecho ${ }^{7}$. En ese instante, el derecho se crea y recrea remitiéndose al propio derecho, que ha llegado a erigirse como sistema con ciertas notas o atributos que no son fruto de ningún azar o ley natural no mediatizada por el lenguaje, sino de teorías cristalizadas pero en permanente evolución, evolución que es la misma de los propios sistemas jurídicos. ¿Acaso puede entenderse la idea de un Estado, con su derecho, sin el concepto «teórico» de soberanía, y la evolución hacia nuevas formas de internacionalización del derecho sin los cambios en aquel concepto? ¿Y pueden pensarse los derechos fundamentales positivados sin todo el sustrato teórico en torno a derechos naturales o derechos humanos? Y las más aireadas de las teorías del derecho serían aquellas que mejor sirven de teorías «para» el derecho, para recrear o respaldar sus estructuras. Piénsese, por ejemplo, en la peripecia doctrinal de la Teoría pura kelseniana o, concretando más el ejemplo, en la

${ }^{4}$ Compárese esto con lo que respecto del discurso moral en general y su ineludible componente teórico en la etapa moral posconvencional, se sostiene en Habermas, J., Gerechtiakeit und Solidarität, en Edelstein, W., Nunner-Winkler, G., Zur Bestimmung der Moral, Frankfurt M., Suhrkamp, 1986, p. 294.

${ }^{5}$ Desde aquí pueden entenderse las caracterizaciones del derecho como la de Uwe Wesel: «si se quiere saber qué es el derecho, contémplese a los juristas: el derecho es lo que se desarrolla en las cabezas de los juristas. La pregunta acerca del derecho se responde de la mejor manera si se descubre cómo trabajan, dónde lo hacen y cómo se representa todo ello en sus cabezas» (Wesel, U., Juristische Weltkunde, Frankfurt M., Suhrkamp, 1984, p. 7).

${ }^{6}$ Por ejemplo, véase Blanke, Th., Recht. System und Moral -Vorüberleaungen zu einer ökologischen Verfassungslehre, en Recht-Justiz-Kritik Festschrift für Richard Schmid, Baden-Baden, Nomos, 1985 , pp. 413 ss.

${ }^{7}$ Cfr. Habermas, J., Teoría de la acción comunicativa, vol. II, Madrid, Taurus, 1987, trad. de M. Jiménez Redondo, p. 265-266. 
relación entre la doctrina de Kelsen sobre el derecho y el desarrollo, como elemento fundamental de los actuales sistemas jurídicos, del mecanismo de control jurisdiccional de constitucionalidad de las normas.

Había dicho que este enfoque del derecho tiene dos virtualidades a la hora de abordar el tema de la epistemología jurídica, y que la primera de ellas consistía en la relativización de la diferencia entre teoría y praxis en el derecho. La segunda consistiría en ofrecer un nuevo baremo a la hora de calificar o clasificar esos conocimientos. Si decimos que la verdad de un discurso jurídico cualquiera es, más que su correspondencia con un estado de cosas presente, su éxito o influjo futuro, por cuanto que todo discurso sobre el derecho que no se pretenda irrelevante, tácita o expresamente cumple un papel en relación con la propia práctica del derecho que describe, las distintas teorías de lo jurídico se podrán catalogar precisamente desde esta óptica de su mayor o menor relevancia pragmática. Y primariamente no se trata de clasificarlas, por ejemplo, como conservadoras o progresistas, o como funcionales o críticas, según que su punto de mira se sitúe en el mantenimiento o transformación del orden jurídico vigente. Se trata más bien de medir su capacidad de incidencia sobre la realidad jurídica y el grado de su conciencia acerca de esa su imbricación con su objeto.

Así, las teorías del derecho se dibujarán como relevantes o irrelevantes. No todas las teorías irrelevantes en relación con el derecho carecen de justificación. Irrelevante para el derecho puede ser una teoría histórica que estudie, por ejemplo, el derecho de los antiguos egipcios sin que de ella se siga o se pretenda extraer consecuencia ninguna para derechos actuales, pero con ello no se pierde la justificación histórica o científica de tal estudio. Pero quien lleva a cabo cualquier género de teoría de lo jurídico que tenga que ver de algún modo con el derecho operante en una sociedad, ya sea sistematizando sus conceptos, mostrando sus antecedentes históricos, analizando la implantación social de sus normas, etc., etc., está incidiendo sobre ese mismo derecho, está su teoría siendo relevante para el mismo, salvo, claro está, en los casos extremos en que como teoría jurídica se presenta algún género de enloquecida especulación, logomaquias sin contacto con realidad ninguna y para las que tampoco cabe esperar el más mínimo eco ${ }^{8}$. Pero, no siendo ese el caso, la etiqueta de mera teoría y de cientificidad sin contaminación práctica puede entenderse como ropaje ideológico o como desconocimiento

${ }^{8}$ Pero hasta eso puede ser funcional por pasiva: quienes así elucubran y cultivan la ficción no cuestionan ni varían de ningún modo la realidad. Que sigan (¿sigamos?), pues, cobrando. 
de la constitución última del objeto cuyo análisis objetivo supuestamente se pretende.

Tenemos, así, que bajo esa perspectiva de la relevancia para la vivencia práctica del derecho en las sociedades, la cuestión, por ejemplo, de la presencia de unas u otras materias en los planes de estudio de derecho es susceptible de un análisis más fructífero que el que resulta de la mera divagación que sólo se pretende teórica. Si el derecho es lo que se dice sobre el derecho, quien controla qué, dónde y bajo qué etiqueta puede decirse acerca del derecho está controlando el único ser posible del derecho, su ser social.

Trataré de pormenorizar un tanto las tesis generales que acabo de exponer. $\mathrm{Si}$ hablamos de conocimiento jurídico, creo que se pueden diferenciar tres tipos básicos de conocimiento del derecho.

Cl. Implicación vivencial ordinaria. Llamo así a la percepción general que de lo jurídico tienen los miembros de una sociedad, como orden que se les impone y en que están insertos. Es ese conocimiento o percepción de la normatividad social y, dentro de ella, de ciertas normas e instituciones que se imponen con una especial fuerza compulsoria. Sería el conocimiento básico y común del derecho, necesario para que este pueda desplegar su función ordenadora de los conflictos sociales. Sea cual sea el tipo de ordenamiento jurídico de que se trate y su relación estructural con otros órdenes normativos vigentes en esa sociedad, el derecho necesita para su funcionamiento de un nivel básico de conocimiento y aceptación de sus reglas, mecanismos e instituciones, cualquiera que sea el resorte que mueva a esa aceptación. En este nivel básico, el derecho se percibe como una vivencia en la que ineludiblemente se está inserto o implicado, en cuanto miembro de un grupo. La vinculatoriedad de ese derecho no necesita asumirse a partir de una operación intelectual que fundamente su justicia, su racionalidad o su justificación última en la garantía de la libertad. El derecho, en este nivel, se vive y se «reconoce» como vinculante por cuanto que se percibe como ineludible. Es el modo normal y habitual en que para el conjunto de la sociedad opera el derecho. Pretender que su vigencia se ampara de hecho en el reconocimiento de su justicia parece un signo de idealismo, de «idealismo heroico» ${ }^{9}$ quizá, loable, pero, desgraciadamente, desenfocado.

${ }^{9}$ Así califica Offe la doctrina habermasiana acerca de la base racional de la comunicación (Offe, C., Bindung, Fessel. Bremse. DieUnubersichtlichkeitvon Selbstbeschränkungsformeln. En Zwischenbetrachtungen im Prozess der Aufkläruna, ed. de A. Honneth, etc. Frankfurt M., Suhrkamp, 1989, p. 757). 
Es posible, por supuesto, que se dé un cierto desfase entre el derecho que se vive en la práctica y el derecho institucionalizado como tal, que haya alguna distancia entre el derecho en la vida y el derecho en los libros, entre el derecho vivo y el derecho estatal, si de sociedades estatales hablamos; pero lo que importa es ver, en la pugna entre discursos que propugnan concepciones o realidades alternativas de lo jurídico, cuál triunfa y se impone efectivamente en la práctica social. Y en esta práctica, en la sociedad tanto de los operadores jurídicos como del común de los que se sienten sometidos al derecho, no se dará la esquizofrenia de sostener que vincula y se aplica un derecho que no es, sin embargo, el verdadero derecho en esa sociedad vigente. Sólo se tendrá por derecho en cada sociedad lo que se diga y funcione como tal, y allí, por ejemplo, donde el derecho natural se predique con éxito y repercusión práctica, será el derecho natural (es decir, lo que se entienda como tal) parte de lo que funcione y se reconozca como jurídico ${ }^{10}$.

C2. Implicación operativa o práctica. Es el tipo de conocimiento de lo jurídico que aparece en los «aplicadores» del derecho u operadores jurídicos organizados, es decir, en quienes «pronuncian» el derecho con efectos prácticos inmediatos de mayor o menor alcance (jueces, abogados, legisladores, notarios, burócratas...). Aquí se da un primer camuflaje de la dimensión creativa del discurso jurídico, como antes se aludió, pues estas figuras operan casi siempre bajo la apariencia de que «pronuncian» un derecho que está escrito o fijado en otra parte. Incluso en el caso del legislador, se desdibuja la dimensión de creación libre o arbitraria de sus productos bajo su reconducción a la soberanía popular y el mandato social, o bajo la ficción epistemológica de la racionalidad del legislador ${ }^{11}$, de un legislador que sería más portavoz de la razón que de sí mismo.

C3. Conocimiento teórico del derecho. Aquí se trataría de aquellos conocimientos del derecho que supuestamente no irían dirigidos a pronunciar el derecho, sino a pronunciarse sobre el derecho, preferentemente en clave analítica y descriptiva. En este apartado entiendo incluidas las doctrinas dogmáticas o de ciencia del derecho, en sentido

${ }^{10}$ Sirva como ejemplo de un enfoque en buena medida similar la siguiente cita de M. Perry: «To say that in American political culture the constitutional text is axiomatically authoritative in constitutional adjudication is to say that, in American politicallegal culture, the proposition 'the constitutional text is authoritative in constitutional adjudication' is not in question» (Perry, M. J. Morality, Politics and Law: A Bicentennial Essay, Oxford, Oxford University Press, 1988, p. 286).

${ }^{11}$ Cfr. Ost, F., van de Kerchove, M., Jalons pour une théorie critique du droit, Bruselas, Facultés universitaires Saint-Louis, 1987, pp. 97 ss. 
restringido, y las teorías y estudios del derecho en términos de ciencia social, como la sociología jurídica. Del porqué de esta común inserción he dado cuanta ya al sostener que todas ellas son corresponsables, aunque tal vez de modo diverso y en distinto grado, de la conformación última que el derecho asuma en la práctica.

Pues bien, la tesis que se sostiene sería que, en tanto entendemos el derecho primaria y originariamente como discurso, como discurso jurídico, como discurso sobre el derecho, C2 y C3 formarían parte de un mismo discurso constitutivo de lo jurídico y destinado a influir sobre $\mathrm{C} 1$. El derecho sería obra de quienes en C2 y C3 lo dicen, del hablar sobre él en esos niveles. Y de los discursos en pugna triunfaría aquel que consiguiera hacerse efectivo en $\mathrm{C} 1$, momento a partir del cual los operadores jurídicos no podrán ya perder de vista que el «derecho vivo», bajo la forma que sea, es aquel que es socialmente acatado y reconocido, por mucho que pueda ese reconocimiento resultar inducido desde los discursos operantes dentro del sistema jurídico mismo. Esto último, el reconocimiento consensual, como derecho, de lo operado dentro de ciertos mecanismos institucionales constituidos por el propio sistema jurídico, sería lo que viene a sostener Luhmann como específico del modo de imbricación social del derecho moderno, esto es, su «legitimación por el procedimiento» o anticipación del consenso social respecto de las decisiones que tengan lugar dentro de la mecánica procedimental e institucional del sistema jurídico diferenciado.

Lo que se viene a mantener aquí, en suma, es la unidad de fondo entre C1, C2 y C3, si bien con la salvedad de que el discurso en $\mathrm{Cl}$ jugaría un doble papel, al tiempo condicionante y subordinado. Condicionante, porque ineludiblemente todo discurso jurídico que no cristalice en práctica y vivencia social efectiva carecerá de relevancia y perderá precisamente esa condición de «juridicidad» o repercusión sobre el derecho. Y subordinado, porque desde el momento en que el derecho se va decantando, frente al sistema social como sistema diferenciado y autónomo, controlando por sí mismo tanto las claves de su propia legitimación formal como las remisiones al cuerpo social para su legitimación material, el discurso jurídico se especializa y autonomiza, con lo que los impulsos y posiciones provenientes del conjunto social le llegan tamizados por su propio sistema de filtros y controles y, en sentido inverso, sus construcciones intelectuales y sus creaciones llegan directamente a la sociedad bajo forma de derecho vinculante, ya sea como normas, como racionalización de esas normas (presentación como sistema, principios, valores...) o como descripción de una mecánica que parte de asumir ciertas prácticas y ciertas construcciones intelectuales como dadas en su condición de jurídicas y como criticables quizá, pero no cuestionables en su ser derecho. 
Así pues, si nos preguntamos cómo es posible el conocimiento jurídico, tendríamos que en C1 la vivencia, la implicación vivencial, la incardinación biográfica en estructuras de normatividad jurídica prima sobre cualquier teorización. Más bien que conocimiento del derecho (en tanto que suspensión teórica de su fuerza vinculante y examen desde el punto de vista de sus condiciones pragmáticas de posibilidad o de alternativas posibles a lo que aquí y ahora se vive como derecho) es posible sólo «reconocimiento» del derecho, asunción de su fuerza inexcusable e incuestionable. Pero en $\mathrm{C} 2$ y C3 no cabe una separación como campos epistemológicamente diversos. Cabe, como máximo, entender que existe una división de papeles a la hora de constituir lo jurídico.

No hay un derecho producto exclusivo de $\mathrm{C} 2$, y menos aún de $\mathrm{C} 1$, preexistente a $\mathrm{C} 3$, a la teoría que lo explica o lo describe. En C2 hay ya un componente teórico esencial, es praxis con teoría presupuesta, y es la teoría, el discurso sobre el derecho, lo que constituye el propio objeto jurídico, principalmente en sus estructuras (configuración del ordenamiento como sistema, principios, valores, conceptos...), pero también en sus contenidos. Son los mismos juristas que «pronuncian» o describen el derecho los que lo crean. Bien sabido es a estas alturas que ni la jurisprudencia ni la dogmática tienen una función exclusiva o prioritariamente exegética, que los parlamentos legitiman políticamente (y es una realidad a la que por mucho que se relativice, no podemos renunciar) lo que juristas conforman en burocracias ministeriales o comisiones codificadoras integradas por los propios juristas dogmáticos o, excepcionalmente, por científicos del derecho, tal como desde hace pocas décadas viene mostrando la joven teoría de la legislación.

El derecho de que se habla lo establece la propia teoría al localizarlo, al crear un estado de opinión que se extiende al propio grupo social y que hace que el origen y caracteres de lo que se piensa y se sanciona como jurídico se sitúe en uno u otro plano de la realidad, vinculado a uno u otro género de realidades. Lo que se viene contemplando habitualmente como teoría y práctica del derecho son partes de una misma realidad conformadora de lo jurídico, si bien con orientación funcional diferente y, en ocasiones, distinto grado de generalidad en sus formulaciones. Una primera consecuencia de esto sería cuestionar la posibilidad misma de una auténtica «teoría» del derecho. Lo único puramente teórico que cabría sería una metateoría del derecho que analizase precisamente el modo como la teoría jurídica es parte de su mismo objeto, contribuye a la configuración del derecho mismo. Y aun de dicha metateoría podríamos cuestionarnos si realmente es ajena, en tanto que desvelación quizá de 
mecanismos sociales de conformación del sistema jurídico, a cualquier influencia sobre la configuración posterior de dicho sistema. ¿Qué ulteriores consecuencias cabe derivar de las tesis expuestas?

En primer lugar, se podría avanzar una hipótesis que rompe con otro de los dualismos imperantes en la doctrina jurídica. Me refiero al dualismo que separa en el derecho entre objeto de legitimación, por un lado, esto es, una determinada configuración del sistema jurídico o los productos de éste, y discurso legitimador, por otro. Frente a ello, cabría suponer que dicha separación entre la legitimación y lo legitimado es parte del discurso legitimante que posibilita el funcionamiento del sistema jurídico. Se apunta, pues, una lectura intrasistemática de los discursos legitimatorios ${ }^{12}$. Pensemos, por ejemplo, en las construcciones doctrinales sobre los fundamentos del orden constitucional, sobre la justificación racional de los derechos fundamentales en cuanto derechos humanos, sobre el Estado de Derecho, sobre la justificación del castigo jurídico, etc. No existirían o no funcionarían de la misma forma las realidades de referencia de esos discursos sin el sostén de los discursos mismos.

Y, con carácter más general, se puede avanzar la hipótesis de que la autonomía del sistema jurídico, característica del derecho moderno, no se mantendría tampoco sin su continua recreación y justificación en discursos que, pretendiéndose meramente teóricos o descriptivos, la dotan de un fundamento o ropaje racional que permite mantener su operatividad. Permítaseme aludir sucintamente a tres recientísimas doctrinas referidas al derecho y que permiten ser interpretadas bajo esta óptica.

a) Luhmann exacerba la autonomía del sistema jurídico ${ }^{13}$. El aumento de complejidad social, es decir, de eventos que acontecen y que

${ }^{12}$ El hecho es que el discurso platónico que inaugura la ciencia no es científico, y eso aunque intente legitimarla. El saber científico no puede saber y hacer saber lo que es el verdadero saber sin recurrir al otro saber, el relato, que para él es el no-saber, a falta del cual está obligado a presuponer por sí mismo y cae así en lo que condena, la petición de principio, el prejuicio» (Lyotard, J.F., $\mathrm{La}$ condición postmoderna, Madrid, Cátedra, 1984, p. 59). «La estabilidad de los órdenes legítimos depende entre otras cosas del factum de que se reconozcan sus pretensiones normativas. Y como quiera que esta validez social guarda una relación interna con las razones y, en términos generales, con el potencial de fundamentación que los sistemas de interpretación, las imágenes del mundo y las tradiciones culturales entrañan, resulta que la elaboración y, sistematización de las imágenes del mundo, que los intelectuales impulsan, tiene consecuencias empíricas» (Habermas, J., Teoría de la acción comunicativa I, Madrid, Taurus, 1987, trad. de M. Jiménez Redondo, p. 256). Véase también Luhmann, N., Theorie der politischen Opposition, en «Zeitschrift für Politik»36/1989, p. 16.

${ }^{13}$ Vid. García Amado, J. A., Introduction a l'oueuvre de Niklas Luhmann, en «Droit et Societé» 11-12/1989, pp. 15-52. 
requieren respuesta del sistema social, habría conducido a que del sistema social global o sociedad se hayan decantado, en el tránsito a nuestra época, subsistemas sociales que se especializan en el tratamiento de parcelas de esa complejidad, con lo que ya no tendrá el conjunto de la sociedad que ocuparse de cada problema, sino que será el sistema científico, por ejemplo, el que se apropie el tratamiento de las cuestiones que requieran ser enjuiciadas en términos de verdad o falsedad, o el sistema jurídico el que de modo exclusivo se reserve el otorgamiento de las notas de legalidad o ilegalidad. Pero esos sistemas se habrían constituido como sistemas cerrados, en cuanto que generan dentro de sí un sentido que los especifica y da a sus claves un alcance que sólo es tal bajo la óptica del propio sistema, de modo que desde el punto de vista de los demás sistemas no es sino parte de un «medio» (Umwelt) que en sí mismo no puede comprenderse por ningún sistema, y del que sólo se extrae por cada uno información en cuanto traducida a su código particular. Así, el sistema jurídico carece de las claves para entender de la verdad o falsedad de los enunciados, y sólo puede ocuparse de la legalidad o ilegalidad de los actos. Cada uno de esos (sub)sistemas se hace autónomo en tanto que opera recursivamente sobre sí mismo: constituye sus propios elementos mediante sus propios elementos. Así, las teorías que en el sistema científico se reputen verdaderas sólo se podrán seguir de otras teorías tenidas también por verdaderas y a tenor de los criterios de verdad que el propios sistema fija; y la legalidad de las normas con que se enjuician en derecho los actos sólo se afirma a partir de los criterios de legalidad que el sistema jurídico fija mediante otras normas. Y el propio Luhmann señala cómo esos sistemas generan teorías de sí mismos como parte de su propia recursividad ${ }^{14}$, como uno de los resortes de fijación del sentido interno que a cada sistema especifica y permite la autonomía funcional de cada uno. Luhmann menciona al respecto, en lo que al sistema jurídico se refiere, la dogmática y la teoría del derecho.

Pero la obra de Luhmann deja abierto uno de sus interrogantes a la hora de ubicarse a sí misma en relación con su objeto, en este caso el derecho. Y en la medida en que pueda pretenderse, cuestión discutible, que es realmente sociología del derecho, queda en pie el tema de la incidencia entre tal disciplina, en su vertiente luhmanniana, y su objeto. Luhmann recabará para si la pertenencia al sistema científico o a un subsistema del sistema de la ciencia; o a un nuevo ámbito del conocimiento ${ }^{15}$. Pero todo ello y la afirmación de la autonomía de los sistemas

${ }^{14}$ Luhmann, N., Soziologische Aufkläruna 4, Opladen, Westdeutscher Verlag, 1987, p. 143.

${ }^{15} \mathrm{La}$ «cibernética de segundo orden» (Luhmann, N., Neuere Entwicklunaen in der Systemtheorie, en «Merkur» 42/1988, p. 297). Y hasta hace uso Luhmann de la 
sociales, como el político o el jurídico, se compagina mal con las tomas de postura «valorativas» de Luhmann $^{16}$, con sus posturas de defensa de los órdenes vigentes ${ }^{17}$, de la racionalidad o la justicia, por ejemplo, de un derecho moderno que nada tendría que ver en cuanto a su funcionamiento con la moral o con las claves operantes en otros sistemas, incluido el sistema científico.

Pero lo que aquí interesa recalcar es cómo Luhmann acentúa la autonomía del sistema jurídico y saca de ello incluso recetas prácticas relativas al modo más conveniente de operar en consonancia con dicha autonomía; por ejemplo, huyendo de la «programación teleológica» de las normas jurídicas ${ }^{18}$, o evitando toda admisibilidad jurídica de cualquier género de desobediencia a las normas o de oposición efectiva al orden jurídico vigente, que no pase por la dinámica electoral bajo el esquema binario gobierno/oposición que preside el sistema político ${ }^{19}$. De este modo, el discurso de Luhmann sobre el derecho puede ser leído como un caso más de discurso que participa en la configuración del objeto que supuestamente se limita a describir. Por poner un ejemplo alejado de sus parámetros teóricos, pero con idéntico esquema de relación entre teoría y praxis, también la doctrina jusnaturalista parte de describir la presunta realidad última de lo jurídico para, en un segundo paso, aconsejar ulteriormente sobre la manera de hacer compatibles aquellos caracteres del objeto en su pureza con las concretas configuraciones del mismo en la práctica.

distinción entre punto de vista interno y externo sobre el derecho, puntualizando que la diferencia clave estaría en que desde este último es posible describir como autorreferencial al sistema observado, el jurídico, que es observado desde ese otro sistema ajeno a él (Luhmann, N., The Sociological observation of the Theory and Practice of Law, I en «European Yearbook in the Sociology of Law» 1/1988, p. 27).

${ }^{16}$ Sobre esa aparente contradicción entre el supuesto punto de vista externo adoptado por Luhmann y posición evaluativa frente a los sistemas que describe, Calhoun, C., Social Theory und the Law: Systems Theory. Normative Justification, and Postmodernism, en «Northwestern University Law Review»83/1989, p. 458.

${ }^{17}$ Vid., por ejemplo, Luhmann, N., Grundrechte als Institution, Berlín, Duncker \& Humblot, 1965, p. 181; Sozioloqische Aufklarung I, Opladen, Westdeutscher Verlag, 4a ed., 1974, p. 108; Gesellschaftsstrukur und Semantik II, Frankfurt M., Suhrkamp, 1981, p. 42; Oekologische Kommunikation, Opladen, Westdeutscher Verlag, 1986, p. 207.

${ }^{18}$ Cfr. Luhmann, N., Zweckbeqriff und Systemrationalitat, Frankfurt M., Suhrkamp, $2^{\mathrm{a}}$ ed., 1987, pp. 101 ss, 257 ss; Sistema jurídico y dogmática jurídica, Madrid, Centro de Estudios Constitucionales, 1983, trad. de I. de Otto, pp. 61 ss.

19 Vid. Luhmann, N., Widerstandsrecht und politische Gewalt, en «Zeitschrift fur Rechtssoziologie» 5/1984, pp. 36-45. Sobre el tratamiento de Luhmann a la desobediencia vid. García Amado, J.A., «Dos visiones de la desobediencia. Ética discursiva contra teoría de sistemas», en Obliqaloriedad y Derecho. XII Jornadas de Filosofía Jurídica y Social, Oviedo, Universidad de Oviedo, 1991, pp. 205 ss, esp. 234 ss. 
b) Un segundo ejemplo, emparentado con el de Luhmann, podemos verlo en las aún más recientes doctrinas acerca del llamado «derecho reflexivo» que tienen su máximo paladín en Gunther Teubner. Para Teubner, el jurista, quien pretende regular la sociedad mediante el instrumental jurídico, tiene que partir de la realidad incontestable de que la sociedad se halla dividida en sistemas funcionales autónomos, cada uno de los cuales funciona a tenor de sus claves y constituye sus elementos mediante sus elementos, regulando sus propias operaciones. Es decir, se trata de sistemas autopoiéticos, en terminología que Teubner toma del último Luhmann. El jurídico es, pues, un sistema autónomo, pero no se puede perder de vista, ni siquiera desde el propio sistema jurídico, que los otros sistemas, sobre los que supuestamente la regulación jurídica ha de incidir, también son autónomos. El peligro que de ello se desprende es triple, planteándose así el ya famoso «trilema regulativo» de que habla Teubner. Toda práctica legislativa pondría en relación tres sistemas distintos y autónomos: el jurídico, el político y aquel que en cada caso se pretende regular. Un derecho que trate de incidir, mediante su regulación, sobre la dinámica interna de otros sistemas (como el económico, el científico, etc.) puede conducir o al predominio del sistema político en detrimento de la autonomía funcional de los otros sistemas implicados, dando lugar a desajustes con el sistema regulado y a la consiguiente falta de efectos sobre éste, tal como ocurriría siempre que la legislación trasluce sólo la llamada función simbólica del derecho; o al predominio del sistema jurídico, igualmente pernicioso por dar lugar a una «sobre legalización» de la sociedad, con efectos desintegradores de la autonomía de los sistemas regulados; o, como tercera posibilidad del trilema, a la supremacía de los propios sistemas sociales que se pretendía regular, lo que conllevaría una «sobresocialización» del derecho y efectos de descomposición de sus propias estructuras, como sucedería cuando su perspectiva propia se ve asaltada por las claves económicas o políticas, etc.» ${ }^{20}$.

Sentada esa autonomía, tanto del jurídico como de los demás sistemas, lo que Teubner propone es un modelo de derecho que, a fin de evitar cualquiera de esos efectos negativos expresados en el trilema, se oriente al cumplimiento de su función de regulación social mediante una práctica normativa que no trate de incidir de modo directo en el funcionamiento interno de ninguno de los sistemas, sino que establezca y asegure únicamente las condiciones contextuales que permiten y

${ }^{20}$ Cfr. Teubner, G., Das Requlatorische Trilemma. Zur Diskussion um post-instrumentale Rechtsmodelle, en «Quaderni Fiorentini per;a Storia del pensiero giurídico»13/1994, pp. 128 ss; After L. aal Instrumentalism? Strategic Models of Post-Regulatory Law, en «International Journal of the Sociology of Law» 12/1984, pp. 311 ss. 
facilitan la operatividad autónoma de cada uno. El único objeto posible de la normación jurídica sería la propia autonomía de los sistemas, que sería así una «autonomía regulada». Se trataría de establecer mecanismos procedimentales para la autorregulación de los sistemas, de manera que éstos puedan maximizar su racionalidad interna mediante los adecuados procedimientos de formación de consenso y decisión colectiva. De ahí que el contenido de esas regulaciones jurídicas consista fundamentalmente en normas organizativas, de procedimiento y de reparto de roles directivos y derechos de participación ${ }^{21}$.

Tal parece, si se me permite la analogía, que el derecho debiera contemplar a cada uno de los restantes sistemas como una especie de sociedad anónima cuya organización se regula pero cuya autonomía decisoria se respeta por encima de todo. Al derecho estatal le estaría desaconsejada (como consecuencia del conocimiento de la autonomía con que cada sistema ha de funcionar y que se ha de respetar si se quiere evitar su crisis) cualquier intervención directa sobre sistemas como el económico. Sólo sería admisible una regulación indirecta, consistente en el «condicionamiento de las condiciones circunstanciales sobre las que se basan los respectivos procesos reflexivos»" ${ }^{22}$, en la «dirección por medio de mecanismos descentralizados de autodirección, respecto de los que el derecho estatal únicamente regula las condiciones de su marco» ${ }^{23}$.

Pensemos en el bien conocido papel que en el proceso teórico que conduce a la afirmación de la autonomía de los sistemas jurídicos modernos juega la filosofía kantiana y en el componente de kantismo que se mantiene en alguna de las elaboraciones teóricas prototípicas de tal idea, como la de Kelsen. Y comparemos con las tesis de Kant, aunque sea de modo trivial y apresurado, algunas de estas ideas que se vienen exponiendo. ¿No recuerda a Kant la idea luhmanniana de que cada sistema sólo puede contemplar la realidad exterior a él, su medio circundante, con arreglo a sus propias claves identificadoras, a tenor de su especifico código, de manera que ninguno puede ver la realidad en sí y al margen de una óptica sistémica determinada, y de manera también que no existe ningún sistema privilegiado, ni siquiera el político, que posea de la sociedad una visión o comprensión de

${ }^{21}$ Cfr. Teubner, G.,Reflexives Recht. Entwicklungsmodelle des Rechts in vergleichender Perspektive, en «ARSP» 68/1982, pp. 28, 49-50, 55; Das Regulatorische Trilemma, cit., p. 123.

${ }^{22}$ Teubner, G., Aspetti. limiti. alternative della legificazione, en «Sociología del Diritto» 12/1985, p, 29.

${ }^{23}$ Teubner, G., Recht als autopoietisches System, Frankfurt M., Suhrkamp, 1989, p.85. 
conjunto y perfectamente objetiva ${ }^{24}$, libre de determinaciones de la perspectiva por los requisitos funcionales del sistema desde el que se observa? Y ese derecho reflexivo de que habla Teubner tal parece un reflejo de aquella función que Kant asignara al derecho como garante de la libertad de cada sujeto, del libre despliegue de sus potencialidades autónomas como sujeto moral, si bien es cierto que en el caso de Teubner (y en el de Luhmann) el sujeto cartesiano, individual, en que pensaba Kant, parece haber sido reemplazado por el sistema autopoético, de manera que el derecho en última instancia se justificaría como garante de la libertad de los sistemas sociales funcionalmente diferenciados para desplegar sus potencialidades de funcionamiento. Se estaría reemplazando así, en la justificación y configuración del derecho, el paradigma del sujeto individual autónomo por el del sistema autónomo, pero manteniendo en lo demás el esquema clásico, de forma que también podríamos parafrasear a Rousseau y decir que se trata de hallar un derecho o un orden social en el que cada sistema al obedecer al derecho no se obedezca más que a sí mismo ${ }^{25}$, de forma que ningún sistema extraeconómico interfiera en la economía, ninguno ajeno a la dinámica electoral de gobierno y oposición en la política, etc.

Teubner insiste en lo desenfocado de las lecturas políticas y economicistas de sus tesis, alegando que no es la suya prioritariamente una toma de postura en el debate jurídico-político, sino una propuesta de funcionamiento para el derecho, consiguiente a la toma de conciencia de que, antes de regular la sociedad, el derecho ha de partir del conocimiento objetivo del modo de funcionar esa sociedad, modo que el propio derecho ha de asumir y no puede por sí mismo modificar ${ }^{26}$. Pero, pese a esa insistencia, es difícil sustraerse a la tentación de ver en esta doctrina algo más que una descripción objetiva y distanciada de la realidad funcional del derecho, de ver en ella también una toma de postura en la lucha entre discursos opuestos, tendentes a configurar de uno u otro modo la realidad jurídica ${ }^{27}$. Teubner, con su particular versión

${ }^{24}$ Luhmann, N., Politische Theorie im Wohlfahrtsstaat, Munich/Viena, Olzog, 1981, p. 121.

${ }^{25}$ Una analogía similar con las doctrinas rousseaunianas acerca del contrato social como mecanismo de compatibilización de la libertad individual con el gobierno de la colectividad, insistiendo en la sustitución del sujeto individual por el sistema autorregulado, se puede ver también en: Blanke, Th., Verrechtlichunq von Wirtschaft. Arbeit und Sozialer Solidarität, en « Kritische Justiz» 21/1988, p. 200.

${ }^{26}$ Teubner, G., Recht als autopoietisches System, cit., pp. 85-86.

${ }^{27}$ El mismo Teubner parece participar de este enfoque, pues reconoce que las expresiones «derecho formal», «derecho material», «derecho reflexivo», etc. no aluden a teorías científicas, sino que son, como expresamente dice, «modelos estratégicos 
de la autonomía del sistema jurídico, estaría proponiendo también un determinado derecho, estaría coadyuvando, con mayor o menor éxito, a ese mecanismo discursivo de creación de la realidad jurídica. Y el triunfo práctico de sus tesis significaría, sin duda, un modo particular de legislar, de entender la función del Estado y, sobre todo, de dar prioridad en la dirección social a la dinámica interna de sistemas como el económico. Al fin y al cabo, la sospecha de neoliberalismo o economicismo en estas posturas se manifiesta con particular claridad en su insistencia en la necesidad de frenar las pretensiones dirigistas de la política y el derecho, desconociendo, o no poniendo suficientemente de relieve, que idénticas pretensiones, y seguramente más eficaces, caben en otros sistemas, como el económico. Tal parece como si bastara con neutralizar la política y su arsenal jurídico, para asegurar una sociedad armónica, de sistemas angélicos, y regida, como no, por la «mano invisible» ${ }^{28}$.

Como tercer ejemplo, de interpretación de teorías que se pretenden del derecho como teorías que, sin embargo, de algún modo se comprometen con o en el derecho tal como existe y se practica, podemos citar las llamadas teorías de la argumentación jurídica, fundamentalmente en su versión alemana, que tienen su mejor expresión en la Theorie der juristischen Argumentation de Robert Alexy y su principal mentor filosófico en Habermas.

El mismo Habermas dedica en los últimos tiempos una atención creciente a la problemática teórica del derecho. Para Habermas, del discurso práctico, que versa sobre pretensiones de corrección normativa, forman parte tanto el discurso moral como el jurídico. En ambos opera el supremo principio de la ética discursiva, que no es otro que una cierta versión del principio de universalización. Se entiende que la fuente primaria que posibilita el orden social, la existencia de sociedad, es el lenguaje, la comunicación lingüística, y que ésta, a su vez, implica

dederecho», que asumen teorías sociológicas del derecho y las transforman en «construcciones jurídicas de la realidad social» (Teubner, G., Das Regulatorische Trilemma, cit., pp. 111-112). Más aún, en palabras del mismo autor, «tales conceptos del derecho son modelos jurídicos internos al derecho-en-la-sociedad, cuya función principal consiste en utilizar la identidad del derecho a fin de desarrollar criterios para su transformación (ibid., p. 112). Tales modelos estarían más allá de las teorías científicas falsables, y «sólo la praxis jurídica misma puede decidir sobre el éxito de tales modelos concurrentes» (ibid., pp. 115- 116).

${ }^{28}$ Para un examen más amplio de las tesis de Teubner, y también de Willke, así como su comparación con la doctrina de Luhmann, cfr. García Amado, J. A., Sociología sistémica y política legislativa, en «Anuario de Filosofía del Derecho» 5/1988 (nueva época), pp. 243-270. 
necesariamente en su práctica ciertos presupuestos pragmáticos o condiciones trascendentales o cuasi trascendentales de posibilidad, consistentes fundamentalmente en que todo hablante presupone, por el hecho mismo de comunicarse con otro, que a su acción comunicativa le es inmanente el «telos» del acuerdo, que el sentido último del acto de habla es la consecución de un entendimiento o consenso que sea fruto únicamente de la libre ponderación de los argumentos en litigio. Así, al lenguaje le subyace como presupuesto la posibilidad de un acuerdo racional, y se actuará tanto más en consonancia con esos presupuestos que tácitamente se asumen al comunicarse, y se incurrirá tanto menos en contradicción pragmática con los mismos, cuanto más se posibilite el despliegue efectivo de esa comunicación y acuerdo racionales y libres de toda coacción, cuanto más se aproximen las comunidades reales en que la comunicación transcurre, a la comunidad ideal de comunicación en que se proyecta la imagen de una plena realización de los presupuestos racionales del habla. Pues bien, Habermas piensa que el discurso jurídico participa de los caracteres generales del discurso práctico o normativo, y que para la racionalidad de sus normas y valoraciones opera el mismo principio de la ética discursiva, expresado en este caso en la idea de que toda norma válida ha de satisfacer la condición de que puedan todos los afectados libremente aceptar las consecuencias y los efectos secundarios que del cumplimiento general se deriven para la satisfacción de los intereses de cada uno.

Pero existiría una peculiaridad de lo jurídico, consistente en el funcionamiento de un doble principio de validez. Junto a la validez racional o justicia de las normas opera en los derechos modernos un modo de validez que les es propio: la validez como legalidad, la validez positiva del derecho. Con ello se desplaza la cuestión del fundamento racional y la acción del discurso práctico en relación con el derecho. Así como en el campo moral cuestionar una valoración supone discutir acerca de la norma en que se basa y analizar esa norma desde el punto de vista de su racionalidad, es decir, de su aptitud para alcanzar un consenso general, en el derecho, cuestionarse sobre el valor normativo de un acto jurídico no es en primer lugar examinar la racionalidad o justicia de la norma respectiva, sino su mera legalidad, su concordancia con el ordenamiento jurídico positivo del que forma parte. Y sólo cuando se discute ese mismo ordenamiento, lo que es tanto como decir, sólo cuando se cuestionan los fundamentos o pilares del ordenamiento jurídico, se penetra en el ámbito del discurso práctico. Por tanto, de las normas o actos en derecho moderno se predicaría su legalidad, pues su justicia o injusticia dependerán de los caracteres del ordenamiento y se medirán a la luz de éstos y no discutiendo directamente la justicia de la 
norma en particular. $\mathrm{Y}$ un ordenamiento es justo y racional, para Habermas, precisamente en la medida en que institucionaliza los postulados de la ética discursiva, es decir en la medida en que provee procedimientos de creación normativa que hacen que las normas que en él se produzcan como legales se puedan entender también como racionales, como justas, en cuanto expresión de un acuerdo libre y, por tanto, de un interés general.

Tenemos así que en Habermas se sanciona la autonomía del derecho respecto de los otros órdenes sociales y se posibilita el distinguir entre lo que es la validez interna o legalidad de las normas y su validez racional o justicia ${ }^{29}$, que lo será la del ordenamientos respectivo, por mucho que, precisamente por esto último, insista Habermas en lo erróneo de la separación tajante, propia del positivismo, entre derecho y moral ${ }^{30}$. Pero, además, Habermas ve en los caracteres del derecho moderno la mejor realización de los postulados de la ética discursiva, justifica sus notas estructurales como expresión de la victoria de esos postulados, precisamente en el campo jurídico, en la edad moderna ${ }^{31}$. A esto se añadiría el que, como mecanismo discursivo, el jurídico posee sobre el moral la ventaja de proporcionar soluciones para problemas tales como el de la delimitación temporal y procedimental de la discusión, evitando su prolongación infinita sin decisión y, además, institucionaliza

${ }^{29}$ Se ha tratado de compatibilizar por esta vía la perspectiva sistémica o funcional con la habermasiana, la racionalidad instrumental con la racionalidad discursiva, identificándolas respectivamente con el punto de vista interno y externo sobre el derecho. De este modo, las dos teorías legitimatorias del derecho moderno, aparentemente opuestas en sus enfoques y presupuestos, se harían simultáneamente utilizables por la teoría que refleja y refuerza ese derecho (Véase Gunther, K., The Idea of Impartiality and the Functional Determinacy of the Law, en «Northwesetrn University Law Review» 83/1989, pp. 169 ss; Aamio, A., The Rational as Reasonable. A Treatise on Legal Justification, Dordrecht, etc., Reidel, 1987, pp. 231 ss). Hasta qué punto puede ser esta una mixtura difícilmente compatible con los planteamientos originarios de Habermas o Luhmann puede verse, por ejemplo en Habermas, J., Teoría de la acción comunicativa II, cit., p. 213-216.

${ }^{30}$ Habermas, J., Wie ist Legitimitat durch Legalität möglich?, en «Kritische Justiz 1987, p.

${ }^{31}$ Se ha llegado a decir que la sustancia moral inscrita en los fundamentos constitucionales de las sociedades occidentales constituyen el verdadero impulso de la filosofía de Habermas, lo cual hace de ésta la versión optimista de la Escuela de Frankfurt, como «teoría de la emancipación abstracta», frente a la dirección pesimista de la misma Escuela, representada por la «Dialéctica de la Ilustración» y que se expresaría como «teoría de la pura dominación» (Dubiel, H., Herrschaft oder Emanzipation? Der Streit um die Erbschaft der Kritischen Theorie, en A. Honneth, etc. (ed.), Zwischenbetrachtungen im Prozess der Aufklarung, Frankfurt M., Suhrkamp, 1989, p. 508). 
instancias decisorias neutrales respecto de los contendientes en cada argumentación, con lo que se hace más factible la finalización del intercambio dialógico en una decisión imparcial y no mediatizada por la acción deformadora de intereses egoístas ${ }^{32}$.

Y lo que las llamadas teorías de la argumentación jurídica vienen a añadir es la insistencia en que la racionalidad de las decisiones jurídicas dependientes de valoraciones dependerá de la dinámica procedimental de la que se $\operatorname{sigan}^{33}$, de modo que si son fruto de un proceso de discusión libre entre sujetos situados ante la discusión en situación paritaria y con iguales derechos ante el discurso, podrán ser tenidas por racionales y no como fruto arbitrario de correlaciones de fuerzas o intereses sesgados.

Son estas sin duda propuestas de las más atrayentes dentro de la actual filosofía del derecho, y la mejor traducción al derecho de la llamada «rehabilitación de la razón práctica», de manera que la problemática principal de que se ocupa, por ejemplo, la metodología jurídica puede ser reinterpretada desde aquí. Pero ello no impide que estas doctrinas puedan, a su vez, relativizarse un tanto y que se contemple el porqué de su aparición o su éxito, y su relevancia para el triunfo de uno $u$ otro modelo de derecho, de una $u$ otra ideología sustentadora del edificio jurídico en sus conformaciones actuales. Y podemos, por de pronto, pensar que toda doctrina que procure mostrar que el derecho o la práctica jurídica son o pueden ser de algún modo racionales (y máxime si se explica que pueden reflejar el acuerdo social de forma que los principios valorativos en que los sistemas jurídicos se apoyan no sean recursos retóricos o ideológicos conceptos vacíos, sino máximas con una virtualidad real) contribuye mucho mejor al sostenimiento o respaldo de tales ordenamientos que la desnuda afirmación de su irracionalidad o de su dependencia de la fuerza, de la manipulación o de designios sistémicos. En ese sentido, como dicen Hase y Ladeur, «el tipo de discurso retórico al que el discurso jurídico pertenece, no tiene primariamente como objeto la «comunicación» racional de conocimientos racionales, sino que tiene un interés vital práctico: la reproducción activa de las relaciones sociales como racionales» ${ }^{34}$.

$\mathrm{Y}$, puesto que en el concepto de racionalidad parece estar la clave de tales elaboraciones teóricas sobre el derecho, podríamos recordar la

${ }^{32}$ Habermas, Wie ist Legitimität durch Legalität möglich?, cit., p. 13.

${ }^{33}$ Vid. Eder, K., Prozedurale Rationalitat, en Zeitschrift für Rechtssoziologie» 7/1986, pp. 1 ss, esp. 20 ss.

${ }^{34}$ Hase, F., Ladeur, K-H., Verfassungsgerichisbarkeit und politisches System. Studien zum Rechtsstaatsproblem in Deutschland, Frankfurt M./New York, Campus. 1980, p. 271. 
opinión de Santayana de que «la idea de racionalidad es en sí misma arbitraria, dependiente de las necesidades de una organización finita o de algún otro ideal. Sólo el aseguramiento último de la tranquilidad del pensamiento, que el filósofo persigue, suscita su necesidad (...) Lo que realmente exige racionalidad, lo que la hace un bien y algo indispensable y le confiere su autoridad, no es su propia naturaleza, sino nuestra necesidad de ella tanto en la acción económica como doméstica, así como en el placer de la comprensión» ${ }^{35}$. Y en esta misma línea, podemos igualmente respaldar la hipótesis de una lectura de las teorías de la argumentación como implicadas en la implantación o defensa del funcionamiento de un determinado tipo de derecho si aplicamos los mismos esquemas que MacIntyre nos muestra al hablar de la moderna tradición liberal sobre el tema de la justicia: como adaptación al sustrato ideológico de una sociedad desideologizada, aparentando que la cuestión de la racionalidad y el orden racional de las preferencias puede tener respuesta ${ }^{36}$. Así, y siguiendo con la inspiración en el autor que acabo de mencionar, cabe reinterpretar la función que en el derecho y su teoría actuales cumple la idea de ponderación, de tanta implantación entre los juristas actuales y entre los cultivadores de la teoría de la argumentación. La concepción de que la base de la moral y el razonamiento práctico (y jurídico) son preferencias personales que pueden ponderarse, estaría en consonancia con los mecanismos de mercado de la política liberal individualista ${ }^{37}$.

La siguiente consecuencia de las tesis expuestas sobre la naturaleza discursiva del derecho y sobre las fuentes también discursivas de su producción, hace referencia a la separación habitual entre punto de vista interno y externo sobre el derecho. Concretamente, lo que conlleva el compromiso de la teoría del derecho en la propia creación y recreación de la realidad así denominada es la duda acerca de la posibilidad de un verdadero punto de vista externo al derecho al hablar sobre el derecho. El criterio aquí puede ser el ya mencionado de la relevancia del discurso sobre su objeto y, en tal sentido, sólo sería realmente externo al derecho, en cuanto que no lo influiría en modo alguno, el estudio puramente histórico sin consecuencias para la comprensión del derecho presente, o el puramente especulativo, que por su misma vacuidad no sea apto ni siquiera como instrumento

${ }^{35}$ Citado por Dunné, J. van, The Role of Personal Values in Legal Reasoning, en «Rechtstheorie», Beiheft 10 (Vernunft und Erfahrung im Rechtsdenken der Gegenwart), 1986, p. 18.

${ }^{36}$ MacIntyre, A., Whose Justice? Wich Rationality?, Londres, Duckworth, 1988. Vid. especialmente pp. 343-344, 384, 398-399.

${ }^{37}$ Vid. Ibid, pp. 337 ss. 
de legitimación de ningún tipo de normas o prácticas jurídicas. Cambiará, desde luego, el grado de implicación del discurso sobre el derecho con la práctica jurídica o con la concreta configuración normativa del ordenamiento, según el grado de distanciamiento del análisis respecto de las normas y las prácticas jurídicas y según su nivel de abstracción. Pero realmente, bajo esta óptica, serían escasas las construcciones teóricas externas a lo jurídico, en cuanto carentes totalmente de repercusión sobre ello. Es difícil asignar, con esta mira, una ubicación en el punto de vista externo a las posturas generales de Kelsen o Ehrlich, por ejemplo, o a los términos de su polémica ${ }^{38}$. Y la misma distinción originaría de Hart entre punto de vista interno y externo puede ser leída más como discurso del derecho o en el derecho que como discurso sobre el derecho, en el sentido de exterior a él. El instrumental analítico mismo sería aquí corresponsable de la configuración de lo analizado, y se haría posible así una cierta lectura «ideológica» de la tesis de Hart, como ya apuntara Tarello hace un par de décadas ${ }^{39}$.

Permítaseme al respecto una comparación quizá demasiado simplista, pero creo que ilustrativa. Quien estudia el folklore de un pueblo puede ser alguien que no cultiva o practica ese folklore, que, por ejemplo, no interpreta o baila, o ni siquiera «vive» sus ritmos. Pero su aportación, si es conocida en ese pueblo y no es absolutamente desenfocada o carente de toda relación con la realidad, influirá sin duda en ese mismo folklore, bien haciéndolo variar de algún modo (por ejemplo para adecuarse mejor a sus orígenes históricos, o a su práctica antigua, o para introducir nuevas variaciones adecuadas a nuevos instrumentos o lugares, etc., etc.) o bien legitimando y fundamentando los caracteres de su cultivo actual. Podrá quizá el antropólogo reivindicar su exterioridad respecto del folklore o el derecho de una cultura primitiva, pero difícilmente estará en la misma situación quien estudia hoy la danza tradicional vasca o quien averigua el componente clasista o no de la administración de justicia. Es difícil que el teórico pueda situarse en esa condición de outsider que MacCormick ejemplifica con los liliputienses que contemplan el

${ }^{38}$ Sobre el modo cómo las polémicas sobre el papel del derecho en la sociedad pueden envolver la polémica en torno a distintas maneras de concebir la producción del derecho, y el derecho mismo, véase Commaille, J., Science et action. Ouelques réflexions sur les relations recherche-practiciens du droit, en «Oñati Proccedings»1/1989 (Legal Culture and everyday life), Ed. A. J. Arnaud, Oñati, Oñati JISL, 1989, p. 73. 41-44.

${ }^{39}$ Tarello, G., La sociologia nella giurisprudenza, en «Sociologia del Diritto» 1/1974, pp. 
reloj de Gulliver ${ }^{40}$. Entre otras cosas, porque los liliputienses no pueden hablar de «reloj», en tanto que Gulliver proviene de una civilización que ha creado el instrumental conceptual, lingüístico, para hablar no sólo de relojes, sino incluso para entender de uno u otro modo el tiempo (aquí podríamos remitirnos a la obra de Norbert Elias que cité al principio). El punto de vista de los liliputienses es externo, pero no en si mismo, sino únicamente desde nuestro punto de vista interno, por la sencilla razón que nosotros (es decir, los miembros de la civilización de la que Gulliver proviene) podemos hablar de reloj, y ellos no, pues sólo el uso lingüístico le da al reloj su condición de tal.

Y si nos referimos al juego de ajedrez como ejemplo, tal como lo mencionan Hart o MacCormick, tendríamos que sólo contemplará los movimientos de dicho juego como simple hábito sin carga normativa ninguna, quien no llame a eso ajedrez, pues para no estar implicado en y con estructuras normativas no basta hacer abstracción analítica de ellas ${ }^{41}$, sino que se precisa ser realmente ajeno a ellas. Más allá de ahí, la división entre ambos puntos de vista o la opción por el trabajo sobre el derecho desde la perspectiva externa, puede entenderse como uno de los modos de actuación interna en el derecho, como uno de los resortes de creación y recreación de lo que en la sociedad se conciba y se aplique como derecho ${ }^{42}$. Y todo lo anterior afectará también al modo de concebir

${ }^{40}$ MacCormick, N., Legal Reasoning and Legal Theory, oxford, Clarendon, 1978, pp. 275 ss. El caso es similar al ejemplo de los habitantes de otro planeta idénticos a nosotros pero que nunca habían visto un árbol, ejemplo con el que Putnam ilustra los problemas de la idea de referencia (Putnam, H., Razón, verdad e historia, Madrid, Tecnos, 1988 (trad. J. M. Estaban), pp. 17 ss.

${ }^{41}$ El punto de vista «externo moderado» que defienden Ost y van de Kerchove se caracterizaría precisamente porque bajo él el observador deja en suspenso su propia adhesión a la obligatoriedad de las normas que examina, pero sin perder de vista esa función normativa que las mismas tienen para los sujetos que se les someten (Ost, F., van de Kerchove, M., op. cit., pp. 75 ss). Por su parte, el punto de vista «hermenéutico moderado» a que se refiere Vittorio Villa (Legal Science and Hermeneutic point of view, en Peczenik, A., Lindahl, L. (eds.), Theory of Legal Science, Dordrecht, Reidel, 1984, pp. 514 ss) consiste en que el científico vea los fenómenos jurídicos como constituidos por los propios miembros de la comunidad jurídica de que se trate, en una permanente labor de «dación» de sentido y de constitución y recreación de «objetos» que no son naturales, sino «culturales» (normas, instituciones, prácticas...). Por contra, mi tesis sería que, con ser cierto lo anterior, ha de radicalizarse yendo más allá: el propio teórico del derecho ha de renunciar a la pretensión de externalidad para su posición, pues sus producciones intelectuales inciden sobre el objeto derecho, condicionan su sentido y su modo de operar.

${ }^{42}$ Arnaud ha resaltado del modo más contundente lo que de mistificación puede contenerse en el empleo de la distinción interno/externo al hablar del derecho, mostrando, por un lado, con la imagen ilustrativa de la banda de Moebius, la intercambiabilidad 
la sociología del derecho y su ubicación epistemológica. Bajo este enfoque tendríamos, recogiendo la famosa distinción, que gran parte de los que se presenta como sociología del derecho sería sociología en el derecho. Para ello, naturalmente, hemos cambiado en buena medida el criterio habitual de referencia. Lo determinante aquí no sería la intención o la ubicación dentro de un esquema meramente analítico ${ }^{43}$, sino la función de las teorías e investigaciones, su grado de imbricación con su mismo objeto. Y el sociólogo del derecho, mejor que vivir atrapado en esa dualidad interior/exterior, podría partir de la autopercepción de la sociología del derecho como parte exterior del interior del discurso jurídico, si se me disculpa el trabalenguas. Y ello conllevaría, además, una importante consecuencia epistemológica y metodológica: la sociología del derecho tendría que autoanalizarse como parte de su análisis de lo jurídico. Y estaría justificada así una sociología jurídica que tuviera como una de sus dimensiones el estudio no sólo de los condicionamientos sociales del derecho, sino incluso de los condicionamientos «jurídicos» de la propia teoría social que se fija en el derecho, en cuanto teoría copartícipe en la producción de su objeto. Parte de la sociología del derecho sería, pues, la sociología de las teorías del derecho, incluidas las sociológicas.

y mutua convertibilidad de ambas perspectivas y, por otro, lo que suponed e toma de partido tanto por una determinada opción epistemológica respecto del componente científico en el estudio del derecho, como por una determinada idea (en la línea de Kelsen o Hart) de la autonomía del derecho respecto de las demás disciplinas o ciencias sociales (Arnaud, A-J., La valeur heuristique de la distinction internelexterne comme grande dichotomie pour la connaissance du droit: élements d'une demystification, en «Droit et Societé» 2/1986, pp. 139-141).

${ }^{43}$ Como dice Ferrari, «cuando distinguimos entre sociología del derecho y jurisprudencia -ciencia del derecho, en realidad no expresamos más que un propósito o un deseo, o una utopía necesaria: la jurisprudencia no «es» prescriptiva, más bien «debe» tratar de serlo. La sociología no «es» descriptiva, más bien «debe» tratar de serlo. Puesto que entre las dos disciplinas no se aprecia una diferencia, debemos tratar de inventarla, de construirla artificialmente» (Ferrari, V., Argomenti per una giurisprudenza selvaggia, en «Sociología del Diritto»13/1986, p. 33). 
